\title{
Analysis of College Students' Network Psychology and Mental Health
}

\author{
Dan Ma \\ Nanyang Institute of Technology, Nanyang, Henan, 473004
}

Keywords: College students; network psychology; Grooming

\begin{abstract}
With the continuous progress of society, China has basically entered the information times, a variety of network tools and network information is full of our lives. Therefore, the current psychological status of college students and their psychological health has attracted more and more attention from the community. This paper describes the current psychological status of college students, analyzes the problems of college students' network psychology, and analyzes the factors that induce the psychological problems of college students. Finally, according to these more prominent problems, the corresponding strategies of mental health are given. This article aims to help college students to actively face their own network problems, and strive to adjust their own psychology, and correctly guide the development of college students' mental health.
\end{abstract}

\section{Introduction}

The network is a multi-edged sword, to people's lives has brought great convenience, but also to people's way of life and thinking on the way to bring a huge impact. And college students as China's construction of society, to promote the development of social fresh blood, in the current era of network problems arising from the network is one of the more critical issues, to the students themselves and the current college style of study and so on Huge impact, has aroused widespread concern in the community. And how to solve the network under the age of college students mental health problems, to enhance the network literacy of college students has become the consensus of the community consensus. And this article on the current college students network psychology and psychological health of the discussion is particularly important.

\section{The Performance of Modern College Students' Network Psychological Problems}

With the continuous progress of our society, China's network technology has been filled with all aspects of people's lives, people are gradually more and more inseparable from the network, and network development in bringing great convenience but also on people's way of life As well as in the psychological produce a subtle change. Which is more serious reflected in the following three aspects:

Own, equality is the goal that people are pursuing. With the advent of the Internet era, people are gradually attracted by their own open, especially in the current college students, a variety of students to meet the spirit of the pursuit of the media and software, such as the gradual rise. Students through the network forum, qq group, micro-credit groups and other channels to express their own comments, to address the current situation, to express demands. However, due to the hidden characteristics of the network between the contacts, so there are many discordant content on the network, and these discordant content will guide the students on the network to indulge their own words and deeds or their own behavior Unethical behavior, thus forgetting the social responsibility, legal responsibility and social ethics and ethics, the moral standards of college students to control the difficulties and confusion on the understanding of morality [1].

In today's society, most of the modern college students for the only child, so in the process of growing up a lot of people lack a certain degree of emotional dependence, so this type of people eager to truth, hope to get approval with their peers. With the popularity of the network, the 
convenience brought about by the network makes it easier for college students to narrow the distance between people and expand their contacts. But there are also dangerous. The network is a virtual environment in which there are many pitfalls and bad information, these traps and bad information for those in daily life or social interaction problems in the students, often the network as a real reality in the real feelings Of the exchange, in order to escape the real life of the problem, which is more caused by the indifference of his interpersonal emotions, coupled with the bad information in the network under the influence of the negative concept of the community is easy to produce, and the character will be more Of the eccentric. In this part of the students, it is in the psychological behavior of the longing for the truth and lonely indifference of the contradictory state [2].

In the current information age, the network brings together the cultural achievements around the world, has become a virtual library for college students to learn knowledge. The rise of network tools also makes modern college students more easily and easily accessible to a variety of information. More than 52\% of college students' information is directly or indirectly derived from the network; $82 \%$ of the students in the search for information on the first thought is the network; $86 \%$ of students through the student-related website Learn to learn. This shows that the network to the students to learn a great benefit.

But also has huge hidden dangers. In the current network because of its existence of a variety of information, so there are many schools to arrange the task of teaching the answer, which led to the students have a lazy psychology of learning, and this also on China to carry out colleges and universities, Cultivate the professional quality of college students run counter to the purpose. At the same time, a variety of online entertainment tools also have an impact on modern college students, making college students addicted to online games and seriously affect their studies. And we in real life for a variety of negative coverage for the Internet addiction is also common [3].

\section{Mental Health Guidance Strategy}

With the entry of our country into the Internet age, the network behavior of college students is gradually diversified. Online shopping, online learning, network chat and so on is the special manifestations of college students' outlook on life and values. In these China, the changes in the language of the network reflect the psychological changes of college students, and can reflect the psychological problems of college students psychological reasons. And the emergence of these network problems on college students' psychology, learning, personality, values, outlook on life and many other have brought harm. Therefore, want to help our current college students to healthy development and it must be based on the existence of college students in the network of psychological problems, the only way to really help college students out of psychological barriers.

Psychological counseling is one of the most effective measures in the university colleges and universities for the network psychological problems, which can effectively guide the development of college students' health network psychology. In colleges and universities, the school can carry out outdoor activities through various means, on the one hand can provide opportunities for communication between college students, on the other hand can also help college students to improve their psychological cognitive ability. For example, through social practice, social surveys and other social activities, so that students actively participate in them, through the students in the activities of the continuous contact with this society, the effective accumulation of college students social experience, to help them improve the problem analysis, problem-solving ability, making College students in the online world which can maintain a rational Internet, not the network of the existence of bad information in the world shaken. At the same time this social practice activities can also effectively help students to promote feelings between. In addition, the school can also establish a psychological counseling group, with some addiction students to group counseling, with the team's strength to help get out of the network [4].

In the management of the school, the school managers and educators need to have a strong ideological and political quality and scientific and cultural knowledge, and requires educators in the work must be students as the core, always concerned about the physical and mental development of 
college students. The students have question in a timely manner to help them establish the correct ideas. And this requires the school to build a number of high-quality, high-quality teachers. These teachers are for a variety of college students on the network psychological issues for the correct guidance. And regular students online record and analysis, and in ideological and political education must also invest a lot of energy, in line with the principle of people-oriented long-term psychological counseling work.

Because there is virtuality in the network, so there are many potential information, and in the current colleges and universities should be its network of moral constraints. The traditional moral education has been difficult to adapt to the change of the network with the change of the times, so it should be innovated in time so that it can restrain the network morality, strengthen the students to correctly establish the outlook on life, values, world view; strengthen the school's cultural construction, To strengthen the training of students in the psychological cognitive ability, to cultivate students noble sentiment, to enrich the campus life of college students to meet the pursuit of college students in the real world to help students shift their excessive dependence on the network to improve the overall quality of college students.

College students still need family education, in order to give students a good room for growth, the school should be actively combined with a few psychological counseling for students, two-pronged approach. And this requires both parents and teachers must have a certain understanding of psychological education knowledge, parents must also actively participate in, through the cooperation with the school teachers, so that students can feel the correct understanding of things, and this cover umbrella Student education environment can also effectively enable students to autonomy to recognize their own problems and timely correction [5].

\section{References}

[1] Jin Xiaoyan. Study on the psychological basis and the countermeasures of college students' internet addiction [J].Technology Monthly, 2016, 01: 52-54.

[2] Huang Hai, Hou Jianxiang, Yu Li, Zhou Chunyan. University students and mobile phone dependence and mental health status of relevance [J]. Chinese School Health, 2014, 11: 1654-1656 $+1659$

[3] Hou Yong. Study on network mental health education of college students [J]. Statistics and Management, 2015, 10: 93-94.

[4] Jiang Guolin. College students network group mental health problems and its buffer intervention [J]. Seeking truth, 2013, S1: 246-247

[5] Cai Jinqing, Chen Fang. Analysis of college students network psychological counseling advantages and disadvantages [J].Vocational Education Research, 2010, 06: 133-134. 